\title{
Physiological serum 25-hydroxyvitamin D concentrations are associated with improved thyroid function-observations from a community-based program
}

\author{
Naghmeh Mirhosseini $\oplus^{1} \cdot$ Ludovic Brunel $^{2} \cdot$ Giovanna Muscogiuri $^{3} \cdot$ \\ Samantha Kimball $\mathbb{B}^{1,4}$
}

Received: 28 June 2017 / Accepted: 4 October 2017 / Published online: 24 October 2017

(C) The Author(s) 2017. This article is an open access publication

\begin{abstract}
Purpose Vitamin D deficiency has been associated with an increased risk of hypothyroidism and autoimmune thyroid disease. Our aim was to investigate the influence of vitamin D supplementation on thyroid function and anti-thyroid antibody levels.

Methods We constructed a database that included 11,017 participants in a health and wellness program that provided vitamin D supplementation to target physiological serum 25-hydroxyvitmain D [25(OH)D] concentrations ( $>100$ $\mathrm{nmol} / \mathrm{L})$. Participant measures were compared between entry to the program (baseline) and follow-up (12 \pm 3 months later) using an intent-to-treat analysis. Further, a nested case-control design was utilized to examine
\end{abstract}

Electronic supplementary material The online version of this article (https://doi.org/10.1007/s12020-017-1450-y) contains supplementary material, which is available to authorized users.

Samantha Kimball

Samantha.kimball@purenorth.ca

Naghmeh Mirhosseini

Naghmeh.Mirhosseini@purenorth.ca

Ludovic Brunel

Ludovic.Brunel@gmail.com

Giovanna Muscogiuri

Giovanna.muscogiuri@gmail.com

1 Pure North S'Energy Foundation, 326 11th Avenue SW, Suite 800, Calgary, AB T2R 0C5, Canada

2 Naturmend Integrative Medical Clinic, 905 1st Ave NE, Calgary, $\mathrm{AB}$ T2E 2L3, Canada

3 IOS and Coleman Medicina Futura Medical Center, via Alcide De Gasperi 107/109/111, 80011 Acerra (Napoli), Italy

4 St. Mary's University, 14500 Bannister Road, Calgary, AB T2X1Z4, Canada differences in thyroid function over 1 year in hypothyroid individuals and euthyroid controls.

Results More than $72 \%$ of participants achieved serum 25 $(\mathrm{OH}) \mathrm{D}$ concentrations $>100 \mathrm{nmol} / \mathrm{L}$ at follow-up, with $20 \%$ above $125 \mathrm{nmol} / \mathrm{L}$. Hypothyroidism was detected in $2 \%$ (23\% including subclinical hypothyroidism) of participants at baseline and $0.4 \%$ (or $6 \%$ with subclinical) at follow-up. Serum $25(\mathrm{OH}) \mathrm{D}$ concentrations $\geq 125 \mathrm{nmol} / \mathrm{L}$ were associated with a $30 \%$ reduced risk of hypothyroidism and a $32 \%$ reduced risk of elevated anti-thyroid antibodies. Hypothyroid cases were found to have higher mean serum $25(\mathrm{OH}) \mathrm{D}$ concentrations at follow-up, which was a significant positive predictor of improved thyroid function.

Conclusion The results of the current study suggest that optimal thyroid function might require serum $25(\mathrm{OH}) \mathrm{D}$ concentrations above $125 \mathrm{nmol} / \mathrm{L}$. Vitamin D supplementation may offer a safe and economical approach to improve thyroid function and may provide protection from developing thyroid disease.

Keywords Thyroid function $\cdot$ Vitamin D $\cdot 25$ -

Hydroxyvitamin D $\cdot$ Autoimmune thyroid $\cdot$ Anti-thyroid antibodies $\cdot$ Hypothyroidism

\section{Background}

Most tissues in the body have vitamin D receptors and thousands of genes are responsive to active vitamin D, 1-25-dihydroxyvitamin $\mathrm{D}\left[1,25(\mathrm{OH})_{2} \mathrm{D}\right]$, suggesting a role for vitamin $\mathrm{D}$ in the normal physiological function of most organ systems, including the thyroid. The thyroid is 
activated through the hypothalamus-pituitary-thyroid axis which is remarkably prone to circadian and seasonal changes [1]. There is seasonal variability to serum thyroidstimulating hormone (TSH) concentrations with the highest levels in autumn-winter and the lowest in spring-summer [2-4]. Vitamin D levels are also affected by seasonal variability and serum 25 hydroxyvitamin D [25(OH)D) levels closely correlate with sun exposure and seasonality, with more vitamin $D$ deficiency $(<50 \mathrm{nmol} / \mathrm{L})$ prevalent during the colder seasons $[5,6]$.

Evidence is increasingly indicating low vitamin D status as a risk factor for autoimmune disease, particularly multiple sclerosis, and including thyroid disease [7-11]. Moreover, TSH levels are closely associated with vitamin D status. During the winter months when vitamin D production is negligible and levels are at a nadir for instance, thyroid cells are less responsive to TSH and, as a result, thyroid hormones (T4) decrease and serum TSH levels increase $[4,12]$. Vitamin D supplementation, targeted at achieving and maintaining serum 25(OH)D levels above $100 \mathrm{nmol} / \mathrm{L}$, may preserve normal human physiology, decrease the risk of autoimmunity and improve immune function in autoimmune disorders [13-16].

Many thyroid disorders have an autoimmune etiology, characterized by a loss of immune system homeostasis [17]. Given the immunomodulatory and anti-inflammatory roles of vitamin D, supplementation may act to suppress autoimmune activity in thyroid disease and improve thyroid function. A recent meta-analysis including 20 case-control studies found that serum $25(\mathrm{OH}) \mathrm{D}$ was lower in individuals with autoimmune thyroid disease (AITD) compared with healthy controls $(\mathrm{OR}=2.99,95 \%$ CI $1.88-4.74)$ and that AITD was more likely to develop with low serum 25(OH)D [18]. Vitamin D deficiency is a common feature in thyroid disorders [19] and low serum 25-hydroxyvitamin D [25 $(\mathrm{OH}) \mathrm{D}]$ concentrations are associated with the development of both Hashimoto's thyroiditis and Grave's disease [20, 21]. The onset and progression of thyroid cancer has been linked with impaired signaling of $1,25(\mathrm{OH})_{2} \mathrm{D}$ through the vitamin D receptor and lower $25(\mathrm{OH}) \mathrm{D}$ concentrations were associated with more severe hypothyroidism [22]. Correcting serum $25(\mathrm{OH}) \mathrm{D}$ status appears to improve thyroid function by reducing circulating thyroid-stimulating hormone (TSH) $[23,24]$.

Thyroid autoimmunity, presenting with increased thyroid autoantibody levels, anti-thyroid peroxidase (anti-TPO) anti-thyroglobulin (anti-TG) antibodies, is associated with vitamin D deficiency [serum $25(\mathrm{OH}) D<50 \mathrm{nmol} / \mathrm{L}$ ] [19, $25,26]$. Despite the scarcity of clinical trials investigating vitamin D supplementation effects on thyroid function, the available studies collectively suggest clinical benefit from vitamin D supplementation in the treatment of autoimmune thyroid disorders with reductions in anti-thyroglobulin
(anti-TG) and anti-thyroid peroxidase (anti-TPO) antibody levels [27-31].

In Canada, one in ten suffer from a thyroid disorder, half of them undiagnosed [32]. Overall, a third of Canadians are vitamin $\mathrm{D}$ deficient $[25(\mathrm{OH}) D<50 \mathrm{nmol} / \mathrm{L}]$ and less than $10 \%$ have levels above $100 \mathrm{nmol} / \mathrm{L}$ [33]. Vitamin D may be an easily modifiable risk factor for autoimmune thyroid disease and supplementation may be used as an adjuvant for treatment [34]. The present analysis utilized a large database of participants in a wellness program receiving vitamin D supplementation, with average doses of $6000 \mathrm{IU} / \mathrm{d}$. We investigated the association between $25(\mathrm{OH}) \mathrm{D}$ status and thyroid function before and after treatment. We further examine differences between hypothyroid and euthyroid patients.

\section{Methods}

\section{Study design and population}

This database analysis is a secondary use of data collected as part of the standard of care for participants in a health and wellness program provided by the Pure North S'Energy Foundation (Pure North), a not-for-profit organization in Calgary, Alberta, Canada. In the Pure North program, participant visits occur approximately yearly and include gathering medical history, consultation and lifestyle recommendations by a health care professional (medical doctor, naturopathic doctor, or nurse practitioner), blood work and anthropometric measurements. A dataset was constructed to include all participant data from January 1st 2010 to December 31th, 2016 who had consented to the use of their anonymized data for research and who met the inclusion criteria. To be included in the dataset participants had to have a program entry measurement for all of the following: $25(\mathrm{OH}) \mathrm{D}$, free T3 (FT3), and T4 (FT4), thyroid stimulating hormone (TSH), anti-TPO, anti-TG, and highsensitivity $\mathrm{C}$ reactive protein (hs-CRP). In addition, the following information was included if it was available: ethnicity, gender, body mass index (BMI), season of the observation (November-April was considered winter and May-October as summer), medical history of thyroid disorders and medications, vitamin D supplementation intake and thyroid symptom measures (described below). To characterize the association between serum 25(OH)D and thyroid function, comparisons were made at baseline and between baseline and follow-up using intent-to-treat analyzes.

Secondly, we utilized a nested case-control design, in which hypothyroid participants (cases, $n=103$ ) were matched in a 1:4 ratio to control participants $(n=412)$ based on age, sex, BMI and the first two digits of their postal code (to 
geographically account for some socioeconomic factors). In this investigation, we examined the effect of serum $25(\mathrm{OH})$ D longitudinally on thyroid function. This study was approved by the Research Ethics Board at St. Mary's University, Calgary (File \# 007FA2017).

\section{Thyroid measures}

Participants were interviewed by a health care practitioner to collect medical history, medication use (iodine, desiccated thyroid or armor thyroid, synthroid or levothyroxine, or any other thyroid medications). To assess suboptimal thyroid function a series of questions were asked during the consultation to evaluate the most common symptoms of hypothyroidism: brain fog, macroglossia, low mood, unrefreshing sleep, cool body temperature, weight gain, and low energy level. Blood work assessed thyroid function measures.

\section{Pure north program and vitamin D supplementation}

The goal of the Pure North program is to optimize health and prevent chronic disease. The Pure North program provides education, lifestyle advice, and nutritional supplements to meet individual requirements. The goal of the program is to achieve optimal nutritional intake with a focus on optimizing vitamin D status, defined as serum $25(\mathrm{OH}) \mathrm{D}$ concentrations $\geq 100 \mathrm{nmol} / \mathrm{L}$. Vitamin D3 supplementation is individualized to target an optimal $25(\mathrm{OH}) \mathrm{D}$ and doses of vitamin D3 are often in excess of the UL (4000 IU/d) given under medical supervision. The data collected as part of this program provided a unique opportunity to investigate the role of a wide range of $25(\mathrm{OH}) \mathrm{D}$ concentrations on thyroid function and autoimmunity.

\section{Laboratory assessments}

Sample preparation and biochemical measurements were performed mostly by Doctor's Data Laboratory, Chicago [DD], a fully accredited laboratory by Clinical Laboratory Improvement Amendments (CLIA). On some occasions, biomarker results were obtained from other certified laboratories (Calgary Laboratory Services, Meridian Valley Lab). All laboratory testing was validated according to ongoing externally provided accreditation test samples.

Serum $25(\mathrm{OH}) \mathrm{D}$ was measured using liquid chromatography and tandem mass spectrometry (LC/MS-MS), with an assay $\mathrm{CV}$ of $2.4 \%$. Thyroid function parameters including serum free triiodothyronine (FT3; reference range: $2.5-5.7 \mathrm{pmol} / \mathrm{L}$ ), free thyroxine (FT4; reference range: 7.7-20.6 pmol/L), Thyroid Stimulating Hormone (TSH; reference range: $0.45-3 \mathrm{mU} / \mathrm{L}$ ), Thyroglobulin (TG; reference range: $\mathrm{M}:<50 \mu \mathrm{g} / \mathrm{L}, \quad F:<30 \mu \mathrm{g} / \mathrm{L})$, anti- peroxidase antibody (anti-TPO; reference range: $<9 \mathrm{kIU} /$ L) and anti-Thyroglobulin antibody (anti-TG; reference range: $<4 \mathrm{kIU} / \mathrm{L}$ ), were measured on a Beckman Coulter automated analyzer, using chemiluminescent immunoassays. Inter-assay CV was $5 \%$ for TSH, $8.3 \%$ for FT3, $3.6 \%$ for FT4, $6.9 \%$ for anti-TPO antibody and $6.6 \%$ for anti-TG antibody. High-sensitivity $\mathrm{C}$ reactive protein (hs$\mathrm{CRP}$; reference range: $<1.0 \mathrm{mg} / \mathrm{L}$ ) was measured using the immunoturbidimetric method with an inter-assay $\mathrm{CV}$ of $2.5 \%$.

\section{Participant subgroups}

Vitamin D deficiency was defined as serum 25(OH)D concentrations $<50 \mathrm{nmol} / \mathrm{L}$ [35] and optimal concentrations $\geq 100 \mathrm{nmol} / \mathrm{L}$ [16]. Subclinical hypothyroidism was defined as serum TSH concentrations $>3 \mathrm{mlU} / \mathrm{L}$, with serum concentrations of FT4 and FT3 within their respective references ranges. Hypothyroidism was defined as serum TSH $>$ $3 \mathrm{mlU} / \mathrm{L}$ with serum FT4 $<10.3 \mathrm{pmol} / \mathrm{L}$ and serum FT3 either within the reference range or $<2.57 \mathrm{pmol} / \mathrm{L}$.

Several patients started thyroid replacement hormones as a results of the testing conducted by Pure North. Participants with undiagnosed or poorly managed hypothyroidism were referred to their family physician. In some cases patients declined referral or follow up, refused treatment, did not comply with medication, or their physician did not believe that replacement hormones were needed at that time. Any change in medication, especially when close monitoring is required to reach an appropriate dose, was done outside of the Pure North program via a primary care practitioner.

There has been some debate on the correct upper limit of the reference range for $\mathrm{TSH}$ concentrations in euthyroid subjects [36-38]. Here we follow the 2002 recommendations of the American Association of Clinical Endocrinologists, we used the upper limit of the serum TSH euthyroid reference range of $3 \mathrm{mlU} / \mathrm{L}$, which represents the $95 \%$ of normal euthyroid population [39]. Also, concentrations above this threshold increase the odds ratio of developing hypothyroidism over the 20 years, especially if thyroid antibodies were elevated [40]. Thyroid autoimmunity was defined as a serum level of anti-TPO $\geq 9 \mathrm{klU} / \mathrm{L}$ and/or antiTG was $\geq 4 \mathrm{klU} / \mathrm{L}[32]$.

\section{Statistical analysis}

Data were analyzed using SPSS version 23 (SPSS Inc., Chicago, IL). Descriptive analyzes were performed to show the distribution of categorical data. Intent-to-treat analyzes was used to compare measures between baseline and follow-up. The results of per-protocol analysis are available upon request. The follow-up average for each biomarker 
was inserted rather than a missing value for those participants who had the baseline value. Paired samples t-tests were performed to evaluate changes in thyroid function measures and other metabolic parameters over time. Independent samples t-tests were utilized to compare mean changes according to compliance groups. Chi-square tests were performed to determine the association between reported thyroid assessment parameters and serum $25(\mathrm{OH})$ D status and vitamin D supplementation dose. Relative Risks (RR) were calculated. Univariate analyzes were used to compare changes in thyroid markers between cases and controls with respect to serum 25(OH)D levels. Binary logistic regressions were performed to look at the association between vitamin D and B12 status with respect to thyroid function measures and to investigate the effect of vitamin D and/or vitamin B12 status on changes in thyroid function over time, considering probable confounding parameters including age, sex, BMI, season of observation, thyroid medication or thyroid-related supplementation. Because serum TSH, anti-TPO, anti-TG and TG levels are higher than the reference range in hypothyroidism and thyroid autoimmune disorders, improvement was defined as decreased levels over time in regression models. In contrast, serum FT3 and FT4 are lower than normal and improvement was defined as an increase in levels. Significance was defined as $p<0.05$.

\section{Results}

\section{Pure north population}

\section{Baseline demographics}

Baseline demographics are presented in Table 1. Mean age was $48 \pm 16$ years with $58 \%$ female $(n=11,017)$. Vitamin D supplement use was reported by $43 \%$ of participants at baseline, greater than the estimates for Canadian of more than 32\% [33]. The BMI distribution was $35.3 \%$ normal $\left(18.5-24.9 \mathrm{~kg} / \mathrm{m}^{2}\right), 36.1 \%$ overweight (25-29.9) and $28.6 \%$ obese $(\geq 30)$ which was in agreement with Canadian population averages [41]. Mean baseline serum 25(OH)D concentrations were $78 \pm 34 \mathrm{nmol} / \mathrm{L}$ with $19 \%$ vitamin D deficient $[<50 \mathrm{nmol} / \mathrm{L}], 80 \%$ below the target $(<100 \mathrm{nmol} / \mathrm{L})$ and $92 \%<125 \mathrm{nmol} / \mathrm{L}$. Serum $25(\mathrm{OH}) \mathrm{D}$ level was significantly lower during the winter season $(61 \pm 28 \mathrm{nmol} / \mathrm{L})$ compared to the summer season $(70 \pm 26 \mathrm{nmol} / \mathrm{L})$ in participants who did not take vitamin D supplements at program entry. Vitamin D deficiency was seen in $37.5 \%$ of these participants in winter and $23 \%$ in summer.

Participants who were vitamin D deficient and did not take any vitamin D supplement at program entry had higher serum TSH in winter $(2.54 \pm 2.6 \mathrm{mU} / \mathrm{L})$ rather than summer
Table 1 Baseline demographics

\begin{tabular}{|c|c|c|}
\hline Parameter & $\mathrm{N}$ & Percentage $(\%)$ \\
\hline Age, years & 11,017 & $48 \pm 16(18-95$ years $)$ \\
\hline Gender & 11,017 & \\
\hline Female & 6378 & 58 \\
\hline Male & 4649 & 42 \\
\hline Body Mass Index, $\mathrm{kg} / \mathrm{m}^{2}$ & 10,554 & $27.6 \pm 5.7$ \\
\hline Normal weight (18.5-24.99) & 3730 & 35.3 \\
\hline Overweight (25-29.99) & 3807 & 36.1 \\
\hline Obese $(\geq 30)$ & 3017 & 28.6 \\
\hline Medication history & 4411 & \\
\hline $\begin{array}{l}\text { Desiccated thyroid (Armor } \\
\text { thyroid) }\end{array}$ & 81 & 1.6 \\
\hline Synthroid & 592 & 13.4 \\
\hline Other thyroid medications & 100 & 2.3 \\
\hline \multicolumn{3}{|l|}{ Supplementation history } \\
\hline Iodine & $1788 / 11,017$ & 14.8 \\
\hline Magnesium & $446 / 8926$ & 4.9 \\
\hline Niacin & $56 / 8779$ & 0.6 \\
\hline Vitamin D & $4694 / 11,016$ & 42.6 \\
\hline \multicolumn{3}{|c|}{ Thyroid Assessment Questionnaire } \\
\hline Brain fog & $3761 / 10,176$ & 37.0 \\
\hline Low energy level & $3643 / 6865$ & 53.1 \\
\hline Macroglossia & $1343 / 9810$ & 13.7 \\
\hline Low mood & $3534 / 10,147$ & 34.8 \\
\hline Unrefreshing sleep & $4993 / 10,329$ & 48.3 \\
\hline Cool body temperature & $3124 / 10,097$ & 30.9 \\
\hline Weight gain & $2715 / 10,004$ & 27.1 \\
\hline Serum $25(\mathrm{OH}) \mathrm{D}$ status, $\mathrm{nmol} / \mathrm{L}$ & 11,017 & \\
\hline$<50$ & 2101 & 19.1 \\
\hline $50-100$ & 6660 & 60.4 \\
\hline $100-150$ & 1867 & 16.9 \\
\hline $150-200$ & 289 & 2.6 \\
\hline $200-250$ & 77 & 0.7 \\
\hline$\geq 250$ & 23 & 0.2 \\
\hline
\end{tabular}

Age and BMI presented as Mean \pm SD

$(2.40 \pm 2.3 \mathrm{mU} / \mathrm{L})(p=0.1)$. Meanwhile, serum FT4 was significantly lower in winter $(14.2 \pm 2.8 \mathrm{pmol} / \mathrm{L})$ compared to summer $(14.8 \pm 2.9 \mathrm{pmol} / \mathrm{L})(p<0.001)$. We found a negative correlation between serum TSH and $25(\mathrm{OH}) \mathrm{D}$ levels [Pearson $r=-0.04, p=0.01]$, indicating that decreased levels of serum 25(OH)D in winter were correlated with increased levels of serum TSH.

\section{Comparison between baseline and follow-up}

We performed a comparison between baseline and followup (12 $\pm 3 \mathrm{mo})$ for 11,017 participants, using Intent-ToTreat analysis. Demographics did not show any significant 
Table 2 Comparison of measures between baseline and one-year follow-up

\begin{tabular}{lllll}
\hline Parameter & $\mathrm{N}$ & $\begin{array}{l}\text { Baseline } \\
(\text { mean } \pm \mathrm{SD})\end{array}$ & $\begin{array}{l}\text { Follow-up } \\
(\text { MEAN } \pm \mathrm{SD})\end{array}$ & P-value \\
\hline FT3 (pmol/L) & 11,017 & $4.9 \pm 0.8$ & $4.6 \pm 0.2^{*}$ & $<0.001$ \\
FT4 (pmol/L) & 11,017 & $14.8 \pm 2.9$ & $13.5 \pm 0.9^{*}$ & $<0.001$ \\
Anti-TPO (kU/L) & 11,017 & $32.2 \pm 92.0$ & $22.4 \pm 41.0^{*}$ & $<0.001$ \\
Anti-TG (kU/L) & 11,017 & $40.1 \pm 112$ & $14.7 \pm 28.7^{*}$ & $<0.001$ \\
TSH $(\mathrm{mU} / \mathrm{L})$ & 110,17 & $2.53 \pm 2.1$ & $2.13 \pm 0.8^{*}$ & $<0.001$ \\
TG $(\mu \mathrm{g} / \mathrm{L})$ & 6509 & $29.2 \pm 27.0$ & $25.1 \pm 5.0^{*}$ & $<0.001$ \\
$\mathrm{hs}-\mathrm{CRP}(\mathrm{mg} / \mathrm{L})$ & 10,968 & $2.71 \pm 4.6$ & $2.40 \pm 2.2^{*}$ & 0.04 \\
25(OH)D (nmol/L) & 11,017 & $78 \pm 34$ & $110 \pm 22^{*}$ & $<0.001$ \\
Vitamin D dose (IU/d) & 11,017 & $1436 \pm 2543$ & $4078 \pm 2936^{*}$ & $<0.001$ \\
\hline
\end{tabular}

${ }^{*} p$-value $<0.001$, Paired t-test, FT3 Free triiodothyronine, FT4 Free thyroxine, anti-TPO anti-thyroid peroxidase antibody, anti-TG antithyroglobulin, $T S H$ thyroid stimulating hormone, $T G$ thyroglobulin, $h s$-CRP high sensitivity $\mathrm{C}$-reactive protein

changes over time, except higher consumption of iodine, magnesium and vitamin D at follow-up, as well as significant improvement in thyroid symptoms like low energy level, macroglossia, unrefreshing sleep and weight gain (Supplementary Table 1). All thyroid measures differed statistically between baseline and follow-up yet mean values for FT3, FT4, TG and TSH remained within their respective reference ranges $(\leq 9 \mathrm{kU} / \mathrm{L}$ for anti-TPO, $\leq 4 \mathrm{kU} /$ $\mathrm{L}$ for anti-TG) (Table 2). There was a weak but significant negative correlation between TSH and thyroid hormones (FT3 and FT4) at both baseline ( $r=-0.08$ for FT4, $r=$ -0.07 for FT3) and follow-up ( $r=-0.07$ for FT4 and $r=$ -0.10 for FT3). Also, changes in thyroid hormones over time were negatively correlated with changes in TSH level $(p<0.001)$. Mean anti-thyroid antibody levels were above their respective reference ranges and were found to be significantly lower at follow-up, with a mean change in antiTPO of $-9.8 \pm 65 \mathrm{kU} / \mathrm{L}$ and anti-TG of $-25.4 \pm 70 \mathrm{kU} / \mathrm{L}$. For those who had elevated anti-thyroid antibody levels, at follow-up $77.5 \%$ were within the reference range for antiTG and $42.2 \%$ for anti-TPO.

Thyroid medication consumption was reported by $15.8 \%$ of participants at program entry and another $3.3 \%$ of participants started taking thyroid medication between entry and follow-up. Using thyroid biomarkers, hypothyroidism was found in $1.8 \%$ of participants at baseline, which is similar to Canadian population estimates of $2 \%$ [32]. At follow-up $0.4 \%$ were classified as hypothyroid. After excluding participants who took thyroid medications at program entry or follow-up, or thyroid medications were initiated some times between entry and follow-up, $1.3 \%$ of participants were hypothyroid at program entry which decreased to $0.3 \%$ at follow-up. Subclinical hypothyroidism (SCH) was detected in $22.1 \%$ of participants at baseline and $5.8 \%$ at follow-up. Again, after excluding participants on thyroid medications at any point during the program, the incidence of SCH decreased from $21.7 \%$ at baseline to $6.1 \%$ at follow-up.

Among those participants who were hypothyroid at baseline, $33.3 \%$ were on thyroid medications at program entry and another $10 \%$ started taking thyroid medications at some point during follow-up. Thyroid medication consumption was reported by $21.3 \%$ of subclinical hypothyroid participants with an additional $6.6 \%$ starting medication later in the program. However, data for medication doses and any change in doses over time is not available in the current study, due to poor patient recall.

Of those with SCH, 91\% had anti-TG antibody titers and $36 \%$ had anti-TPO antibody titers above the reference range. In addition, $26 \%$ of $\mathrm{SCH}$ had inflammation (hs$\mathrm{CRP} \geq 3 \mathrm{mg} / \mathrm{L}$ ). Participants who presented thyroid symptoms like weight gain, cool body temperature, low mood, brain fog and refreshing sleep, had significantly higher T4 levels compared to those who did not present the symptoms. Among those participants who had high TSH levels at baseline ( $\geq 3 \mathrm{mlU} / \mathrm{L}$ ), there was a significant negative correlation between $\mathrm{T} 4$ and the majority of hypothyroid symptoms, revealing that with increasing T4 levels, the incidence of presenting brain fog $(r=-0.125)$, low mood $(r=-0.120)$, unrefreshing sleep $(r=-0.133)$, cool body temperature $(r=-0.060)$ and weight gain $(r=-0.102)$ were significantly decreased.

Participants were considered at-risk for autoimmune thyroid disease (ATD) when anti-thyroid antibody levels were above the reference range. Considering anti-TPO, 32\% were at-risk at baseline which decreased to $20 \%$ at followup. For anti-TG, 93\% of participants were at-risk at baseline down to $21 \%$ at follow-up. Concomitant high levels of antiTPO and anti-TG were present in $29 \%$ of participants at baseline and $9 \%$ at follow-up. Overall, for those at-risk for ATD at baseline, more than $60 \%$ were no longer considered at-risk at follow-up. In contrast, for those who had normal levels of antibodies at baseline, the chance of being at risk for ATD at follow-up was $1 \%$.

After 1 year in program, mean serum 25(OH)D concentrations significantly increased, from $78 \pm 34 \mathrm{nmol} / \mathrm{L}$ to $110 \pm 22 \mathrm{nmol} / \mathrm{L}$, and was consistent with the increase in vitamin D supplementation dose, from $1436 \pm 2543 \mathrm{IU} / \mathrm{d}$ to $4078 \pm 2936 \mathrm{IU} / \mathrm{d}$ at follow-up (Table 2). At follow-up serum $25(\mathrm{OH}) \mathrm{D}$ levels $\geq 100 \mathrm{nmol} / \mathrm{L}$ were achieved by $86 \%$ of participants with a mean intake of $3940 \pm 2660 \mathrm{IU} / \mathrm{d}$. Moreover, $11 \%$ had serum $25(\mathrm{OH}) \mathrm{D}$ levels $\geq 125 \mathrm{nmol} / \mathrm{L}$ with a mean intake of $6164 \pm 4398 \mathrm{IU} / \mathrm{d}$.

Subclinical hypothyroid cases $(\mathrm{SCH})$ were investigated in comparison with hypothyroid patients and participants with normal thyroid function. Following significant increase in serum $25(\mathrm{OH}) \mathrm{D}$ levels, we found significant improvements in thyroid antibodies and TSH, with no change in 
thyroid hormones for SCH (Supplementary Table 2). This improvement was more pronounced in hypothyroid patients rather than $\mathrm{SCH}$ cases.

\section{Vitamin D, thyroid measures, and inflammation}

We examined the risk of autoimmune thyroid disease and hypothyroidism with respect to measurable changes in 25 $(\mathrm{OH}) \mathrm{D}$ levels to investigate whether thyroid measure improvements were associated with the intervention program. The relative risks for increased levels of anti-TPO, anti-TG, and inflammation (hs-CRP) were found to be significantly lower when serum 25(OH)D levels $\geq 125$ $\mathrm{nmol} / \mathrm{L}$ were achieved. Serum $25(\mathrm{OH}) \mathrm{D}$ concentrations $<125 \mathrm{nmol} / \mathrm{L}$ were associated with an increased risk of thyroid disease, a $115 \%$ increased risk of elevated anti-TG antibody, $118 \%$ increased risk of anti-TPO antibody and $107 \%$ increased risk of elevated TSH. Serum 25(OH)D levels above $125 \mathrm{nmol} / \mathrm{L}$ were associated with 60 and $14 \%$ less chance of having low levels of thyroid hormones (FT4 and FT3) (Table 3).

Inflammation (hs-CRP $>3 \mathrm{mg} / \mathrm{L}$ ) was present in $17 \%$ of participants with high anti-TG, $8 \%$ with high anti-TPO and $6 \%$ of participants with both anti-TG and anti-TPO above the reference range (Fig. 1).

Thyroid assessment questionnaire was completed by $n=$ 3367 participants at entry to the program and again 1 year follow-up. Both vitamin D supplementation dose and serum $25(\mathrm{OH}) \mathrm{D}$ levels were found to significantly reduce the risk of reported hypothyroid symptoms at follow-up (Table 4). The relative risk of reporting brain fog, low mood, unrefreshing sleep, weight gain or low energy was significantly higher in participants whose serum 25(OH)D level were $<125 \mathrm{nmol} / \mathrm{L}$ after 1 year in program, compared to those with serum $25(\mathrm{OH}) \mathrm{D}$ levels $\geq 125 \mathrm{nmol} / \mathrm{L}$. Vitamin $\mathrm{D}$ supplementation dose $\geq 4000 \mathrm{IU} / \mathrm{d}$ was associated with lower risk of reporting brain fog, low mood, unrefreshing sleep, weight gain, and low energy.

\section{Nested case-control study}

\section{Baseline characteristics}

To examine the relationship between serum $25(\mathrm{OH}) \mathrm{D}$ status and improved thyroid function we compared, in a 1:4 ratio, hypothyroid cases $(n=103)$ to euthyroid controls $(n=412)$ matched based on age, sex, BMI and the first two digits of their postal code. Hypothyroid cases were defined based on their measured thyroid biomarkers (TSH, FT3, and FT4). Participants taking thyroid medication at program entry or follow-up (desiccated thyroid and synthroid) were excluded. Intervention between baseline and follow-up included vitamin $\mathrm{D}$ and multivitamin package. As expected hypothyroid individuals had higher levels of TSH, anti-TPO, and anti-TG, lower levels of FT3 and FT4, and more frequently reported brain fog, unrefreshing sleep, and weight gain (Supplementary Table 3). The reported history of vitamin and supplement use was not significantly different between hypothyroid and control groups. However, at baseline, serum 25(OH)D was significantly lower in cases than controls $(68 \pm 32$ vs. $82 \pm 34 \mathrm{nmol} / \mathrm{L}$; $p$-value $<0.001)$.

\section{Biomarker changes}

Serum 25(OH)D concentrations increased to a greater extent in hypothyroid cases compared to the controls (mean change $42 \pm 26$ vs. $28 \pm 31 \mathrm{nmol} / \mathrm{L}$, respectively, $p$-value $<0.001$ ), whereas vitamin $\mathrm{D}$ supplementation doses were lower at $3517 \pm 2620 \mathrm{IU} / \mathrm{d}$ in cases compared to $4150 \pm$ $3321 \mathrm{IU} / \mathrm{d}$ in controls ( $p$-value 0.05 ). Among hypothyroid

Table 3 Relative risk (RR) for thyroid condition worsening according to serum 25(OH)D level and vitamin D supplementation dose at one-year follow-up

\begin{tabular}{|c|c|c|c|c|c|c|}
\hline & \multicolumn{3}{|c|}{$\begin{array}{l}\text { Relative risk }(95 \% \mathrm{CI}) \text { based on serum } 25(\mathrm{OH}) \mathrm{D} \text {, } \\
\mathrm{nmol} / \mathrm{L}[n=11,017]\end{array}$} & \multicolumn{3}{|c|}{$\begin{array}{l}\text { Relative risk }(95 \% \mathrm{CI}) \text { based on vitamin D supplement dose, } \\
\mathrm{IU} / \mathrm{d}[n=11,017]\end{array}$} \\
\hline & $<125(n=9796)$ & $\geq 125(n=1226)$ & $P$ value $^{\mathrm{a}}$ & $<4000(n=8215)$ & $\geq 4000(n=2806)$ & $P$ value $^{\mathrm{a}}$ \\
\hline FT3 decrease & $1.02(1.002-1.029)$ & $0.88(0.793-0.983)$ & 0.02 & $1.02(1.003-1.049)$ & $0.93(0.869-0.991)$ & 0.03 \\
\hline FT4 decrease & $1.56(1.377-1.773)$ & $0.95(0.938-0.963)$ & 0.01 & $1.39(1.292-1.501)$ & $0.90(0.882-0.921)$ & $<0.001$ \\
\hline Anti-TPO increase & $1.18(1.158-1.202)$ & $0.32(0.291-0.360)$ & $<0.001$ & $1.60(1.545-1.653)$ & $0.34(0.316-0.358)$ & $<0.001$ \\
\hline Anti-TG increase & $1.15(1.132-1.172)$ & $0.37(0.331-0.409)$ & $<0.001$ & $1.49(1.445-1.536)$ & $0.37(0.352-0.399)$ & $<0.001$ \\
\hline TSH increase & 1.07 (1.058-1.087) & $0.55(0.495-0.621)$ & $<0.001$ & $1.20(1.172-1.224)$ & $0.57(0.536-0.615)$ & $<0.001$ \\
\hline TG increase & $1.02(0.998-1.035)$ & $0.89(0.776-1.015)$ & 0.08 & $1.04(1.007-1.071)$ & $0.90(0.832-0.978)$ & 0.01 \\
\hline hs-CRP increase & $1.12(1.099-1.132)$ & $0.43(0.385-0.479)$ & $<0.001$ & $1.28(1.245-1.309)$ & $0.51(0.477-0.543)$ & $<0.001$ \\
\hline
\end{tabular}

FT3 Free triiodothyronine, FT4 Free thyroxine, anti-TPO anti-thyroid peroxidase antibody, anti-TG anti-thyroglobulin, TSH thyroid stimulating hormone, $T G$ thyroglobulin, $h s$ - $C R P$ high sensitivity C-reactive protein

${ }^{a}$ Chi Square test 

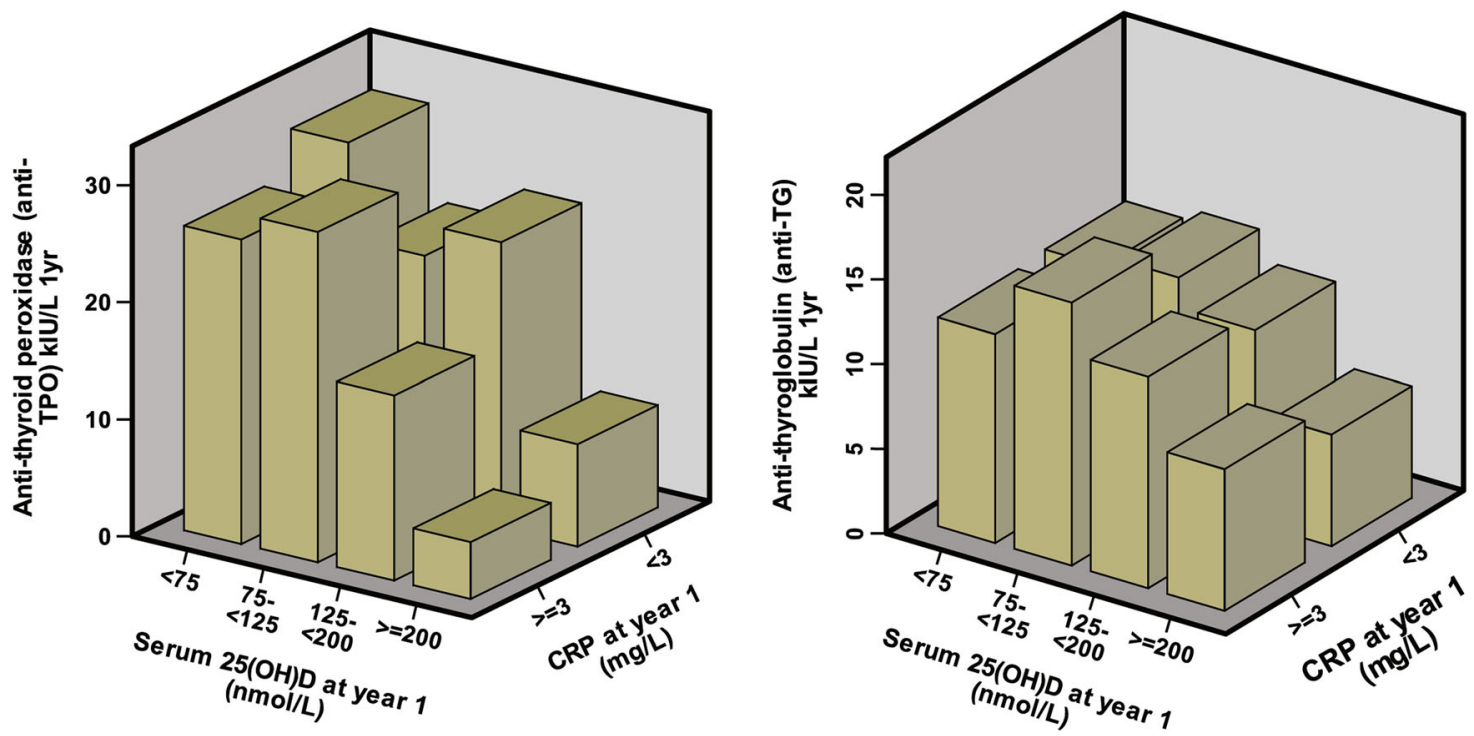

Fig. 1 Relationship between anti-thyroid antibody levels, serum 25(OH)D and C reactive protein (hs-CRP). Left Panel, anti-TPO; Right Panel, anti-TG

Table 4 Relative risk for reported thyroid symptoms in accordance to serum 25(OH)D level and vitamin D supplementation dose at one-year follow-up

\begin{tabular}{|c|c|c|c|c|c|c|}
\hline & \multicolumn{3}{|c|}{ Relative risk based on serum $25(\mathrm{OH}) \mathrm{D}, \mathrm{nmol} / \mathrm{L}(n=3367)$} & \multicolumn{3}{|c|}{$\begin{array}{l}\text { Relative risk based on vitamin D supplement dose, IU/ } \\
\mathrm{d}(n=3367)\end{array}$} \\
\hline & $<125(n=2389)$ & $\geq 125(n=978)$ & $P$ value $^{\mathrm{a}}$ & $<4000(n=1001)$ & $\geq 4000(n=2366)$ & $P$ value $^{\mathrm{a}}$ \\
\hline Brain fog & $1.053(1.007-1.10)$ & $0.88(0.783-0.987)$ & 0.03 & $1.13(1.012-1.25)$ & $0.95(0.905-0.996)$ & 0.03 \\
\hline Macroglossia & $1.109(1.023-1.204)$ & $0.75(0.571-0.977)$ & 0.02 & $1.09(0.866-1.34)$ & $0.97(0.877-1.07)$ & 0.5 \\
\hline Low mood & $1.09(1.042-1.144)$ & $0.79(0.698-0.903)$ & $<0.001$ & $1.2(1.07-1.34)$ & $0.92(0.875-0.972)$ & 0.002 \\
\hline Unrefreshing sleep & $1.09(1.046-1.14)$ & $0.80(0.719-0.895)$ & $<0.001$ & $1.18(1.06-1.305)$ & $0.93(0.89-0.97)$ & 0.002 \\
\hline Cool body temperature & $0.99(0.947-1.045)$ & $1.012(0.903-1.135)$ & 0.8 & $1.00(0.895-1.13)$ & $0.99(0.95-1.05)$ & 0.9 \\
\hline Weight gain & $1.18(1.12-1.23)$ & $0.62(0.522-0.733)$ & $<0.001$ & $1.27(1.13-1.44)$ & $0.89(0.835-0.95)$ & $<0.001$ \\
\hline Low energy & $1.35(1.18-1.548)$ & $0.89(0.855-0.935)$ & $<0.001$ & $1.05(1.01-1.106)$ & $0.89(0.794-0.999)$ & 0.05 \\
\hline
\end{tabular}

${ }^{\text {a }}$ Chi square test

cases optimal $25(\mathrm{OH}) \mathrm{D}$ concentrations $(>100 \mathrm{nmol} / \mathrm{L})$ were achieved in $92 \%$ at follow-up, up from $15 \%$ at baseline, whereas $80 \%$ of controls achieved optimal levels (up from $26 \%$ ). In comparison with controls, cases had significantly greater decreases in levels of TSH, anti-TPO, anti-TG, and greater increase in thyroid hormones concentrations (FT4 and FT3) (Table 5). Hypothyroid cases $(n=69)$ that were vitamin $\mathrm{D}$ insufficient at baseline had greater decrease in anti-TPO ( $-144 \pm 164$ vs. $-2.7 \pm 71)$, TSH $(-4.0 \pm 4.8$ vs. $0.2 \pm 0.7)$ and greater increase in FT4 (4.5 \pm 1.4 vs. $-1.2 \pm$ $2.9)$ in comparison with those who were vitamin $D$ sufficient $(n=34)$ [anti-TPO $(-68 \pm 103$ vs. $-3 \pm 71)$, TSH $(-2.3 \pm 2.9$ vs. $0.2 \pm 0.8)$ and FT4 (3.4 \pm 1.4 vs. $-0.3 \pm$ $0.7)]$.

We also compared hypothyroid cases who were vitamin $\mathrm{D}$ deficient [serum $25(\mathrm{OH}) D<75 \mathrm{nmol} / \mathrm{L}$ ] and not taking thyroid medication with a hypothyroid control group who were vitamin D sufficient [serum 25(OH) $D \geq 75 \mathrm{nmol} / \mathrm{L}]$ and on no medication, in a ratio of $1: 4$, age-matched, sex-matched, and BMI-matched (Supplementary Table 4). At program entry, serum FT4 was significantly lower and anti-TPO and anti-TG levels were significantly higher in hypothyroid cases who were vitamin D deficient compared to control group. After 1 year followup, hypothyroid cases who were vitamin $\mathrm{D}$ deficient had less of a decrease in FT4 $(-0.12 \pm 2.7$ vs. $-1.1 \pm 2.3)$, and a greater decrease in anti-TPO $(-28.1 \pm 83.9$ vs. $-13.1 \pm$ $77.8)$ and anti-TG $(-84.5 \pm 107$ vs. $-37.9 \pm 118.7)$. Further, cases had a significantly greater increase in serum 25 $(\mathrm{OH}) \mathrm{D}$ level $(47.8 \pm 20.8$ vs. $12.0 \pm 33.7)$ and greater decrease in hs-CRP $(-0.97 \pm 7.0$ vs. $-0.06 \pm 4.0)$ than controls. 
Table 5 Comparison of thyroid measures over time between cases and controls

\begin{tabular}{|c|c|c|c|c|c|c|c|}
\hline \multirow[t]{2}{*}{ Serum parameter } & \multicolumn{3}{|l|}{ Case } & \multicolumn{3}{|c|}{ Control } & \multirow{2}{*}{$\begin{array}{l}\text { Between groups } \\
\text { comparison }(P \text {-value })^{2}\end{array}$} \\
\hline & $N$ & $\begin{array}{l}\text { Baseline } \\
(\text { mean } \pm \mathrm{SD}\end{array}$ & $\begin{array}{l}\text { Follow-up } \\
(\text { mean } \pm \mathrm{SD})\end{array}$ & $N$ & $\begin{array}{l}\text { Baseline } \\
(\text { mean } \pm \mathrm{SD})\end{array}$ & $\begin{array}{l}\text { Follow-up } \\
(\text { mean } \pm \mathrm{SD})\end{array}$ & \\
\hline FT3 (pmol/L) & 103 & $4.34 \pm 0.6$ & $4.57 \pm 0.2^{\mathrm{b}}$ & 412 & $4.85 \pm 0.7$ & $4.30 \pm 0.5^{\mathrm{b}}$ & $<0.001$ \\
\hline FT4 (pmol/L) & 103 & $9.06 \pm 1.1$ & $13.4 \pm 1.0^{\mathrm{b}}$ & 412 & $14.7 \pm 2.8$ & $13.5 \pm 1.0^{\mathrm{b}}$ & $<0.001$ \\
\hline Anti-TPO (kU/L) & 103 & $162.8 \pm 120$ & $43.4 \pm 116^{\mathrm{b}}$ & 412 & $21.5 \pm 54.8$ & $18.8 \pm 26.7$ & $<0.001$ \\
\hline Anti-TG (kU/L) & 103 & $51.8 \pm 33.7$ & $17.6 \pm 27.2^{\mathrm{b}}$ & 412 & $32.0 \pm 61.3$ & $14.5 \pm 30.7^{\mathrm{b}}$ & 0.05 \\
\hline TSH (mlU/L) & 103 & $5.97 \pm 4.2$ & $2.50 \pm 1.1^{\mathrm{b}}$ & 412 & $1.78 \pm 0.7$ & $1.98 \pm 0.6^{\mathrm{b}}$ & $<0.001$ \\
\hline $\mathrm{TG}(\mu \mathrm{g} / \mathrm{L})$ & 31 & $43.1 \pm 39.4$ & $25.6 \pm 4.0^{\mathrm{b}}$ & 244 & $28.2 \pm 26.3$ & $25.4 \pm 5.9$ & 0.003 \\
\hline hs-CRP (mg/L) & 103 & $2.05 \pm 2.2$ & $2.52 \pm 1.4$ & 412 & $2.35 \pm 3.1$ & $2.41 \pm 1.9$ & 0.2 \\
\hline 25(OH)D (nmol/L) & 103 & $68 \pm 32$ & $110 \pm 14^{\mathrm{b}}$ & 412 & $82 \pm 34$ & $110 \pm 27^{b}$ & 0.001 \\
\hline Vitamin D dose (IU/day) & 103 & $1243 \pm 2606$ & $3517 \pm 2620^{\mathrm{b}}$ & 412 & $1824 \pm 2770$ & $4150 \pm 3321^{b}$ & 0.9 \\
\hline
\end{tabular}

a Independent samples $T$-test (between groups comparison)

${ }^{\mathrm{b}} P<0.05$ paired samples $T$-test (within group comparison)

\section{Relationship between vitamin D status and thyroid function}

After 1 year in program, changes in thyroid measures differed significantly between hypothyroid cases compared to controls (Table 5). Larger decreases in TSH, anti-TPO, and anti-TG were found for cases. Among vitamin D-deficient cases, an increased serum $25(\mathrm{OH}) D \geq 50 \mathrm{nmol} / \mathrm{L}$ was associated with greater reductions in biochemical signs of hypothyroidism and thyroid autoimmune disease including an increase in FT4 and FT3, and large decrease in serum TSH, anti-TPO, anti-TG, and TG (Supplementary Table 5).

We utilized binary logistic regression to determine the effect of serum $25(\mathrm{OH}) \mathrm{D}$ on changes in thyroid measures (Supplementary Table 6). Thyroid measures were corrected for age, sex, BMI, season of observation and thyroid medication use. Regression analysis revealed that serum 25 (OH)D improvement to above $75 \mathrm{nmol} / \mathrm{L}$ had a significant positive association with decreased serum TSH $(\beta=1.135$, 95\% CI 1.002-1.353), decreased anti-TPO ( $\beta=1.950,95 \%$ CI $1.351-2.815)$, decreased anti-TG $(\beta=1.445,95 \% \mathrm{CI}$ $1.002-2.091)$ and increased FT4 $(\beta=1.413,95 \%$ CI 1.006-2.129) levels. Moreover, serum vitamin B12 improvement had a significant association with increased serum FT4 ( $\beta=1.737,95 \%$ CI 1.387-2.176) and increased FT3 $(\beta=1.469,95 \%$ CI $1.203-1.794)$ levels. Serum TSH level varied seasonably with significantly lower levels during the winter season. These changes were independent of changes affecting FT3 and FT4.

\section{Discussion}

Approximately $2 \%$ of participants in this health and wellness program were found to be hypothyroid at program entry, with an additional $22 \%$ classified as subclinical hypothyroid. High incidence of subclinical hypothyroidism in this study population might explain $15.8 \%$ of participants that reported thyroid medication use. Like other studies [25, 42,43 ], we found that hypothyroid individuals were three times more likely $(27 \%)$ and subclinical hypothyroidism nearly twice as likely (17\%) to be vitamin D-deficient than euthyroid individuals (10\%). Supplementation with vitamin $\mathrm{D}$ resulted in an overall reduction in TSH and in the detection of hypothyroidism (down 58\% at follow-up). Most intriguing was the finding that subclinical hypothyroidism was reduced by $72 \%$ at follow-up. It is well accepted that subclinical hypothyroidism is a mild, early form of thyroid failure [44]. Achieving serum 25(OH)D concentrations above $125 \mathrm{nmol} / \mathrm{L}$ reduced the risk for high TSH as well as symptoms of low thyroid function (brain fog, weight gain, low mood, unrefreshing sleep and low energy). These results are consistent with clinical trials centered on patients with autoimmune thyroid diseases showing that thyroid antibodies decreased significantly following vitamin D supplementation compared to patients receiving no vitamin D [27, 29]. In combination with these studies, our findings suggest that vitamin D may influence thyroid function and that supplementation may be used as an intervention to help prevent hypothyroidism. We also found that $76 \%$ of hypothyroid patients were vitamin B12 insufficient (serum vitamin B12 <450 pmol/L) and improving serum vitamin B12 status was significantly associated with increased thyroid hormones (FT3 and FT4). Replacement of B12 might lessen hypothyroid symptoms. Jabbar et al. [45] and Al-Khamis [46] previously showed that there is a high prevalence of vitamin B12 deficiency in hypothyroid patients and replacing vitamin B12 improves their symptoms. 
The current study revealed that serum TSH is significantly affected by season and is the highest in winter, when average serum $25(\mathrm{OH}) \mathrm{D}$ concentrations were at their lowest. Moreover, this association was independent of thyroid hormones and yet was dependent on improvements in serum $25(\mathrm{OH}) \mathrm{D}$ status. Considering the high prevalence of vitamin D deficiency worldwide and the high incidence of undiagnosed subclinical hypothyroidism in the general population (as we found in Canadians), the existence of the association between TSH and vitamin D status is of high importance and makes vitamin D supplementation a potential asset for patients already taking thyroid medications.

Autoimmune thyroid disease (AITD), including Grave's disease and Hashimoto's thyroiditis, are prevalent autoimmune disorders affecting an estimated 5\% of the population [47]. A link between hypovitaminosis D and thyroid autoimmunity has been established [23] and a review of 20 case-control studies revealed that lower levels of $25(\mathrm{OH}) \mathrm{D}$ were prevalent in autoimmune thyroid diseases [18]. We found elevated anti-thyroid antibodies, both anti-TPO and anti-TG, in $29 \%$ of the population considered at-risk for developing autoimmune thyroid disease, over $80 \%$ of whom did not have optimal $25(\mathrm{OH}) \mathrm{D}$ levels $(>100 \mathrm{nmol} / \mathrm{L})$ at baseline.

Proper thyroid function requires appropriate physiological levels of serum 25(OH)D (i.e., 100-130 nmol/L) [16]. It has been suggested that physiological levels should be sustained for a considerable period of time (e.g., 2-3 years) for the goal of chronic disease prevention or treatment achieved [48]. In accordance, we also found that of the subjects who achieved serum 25(OH)D above $100 \mathrm{nmol} / \mathrm{L}$ at follow-up, roughly 1 year after program entry, only $8.8 \%$ were still considered at-risk of AITD. Given that AITD is the main cause of thyroid dysfunction in Canada [49], the remarkable decrease in thyroid autoantibodies following improved serum $25(\mathrm{OH}) \mathrm{D}$ status might explain the significant decrease in the prevalence of hypothyroidism (from 2 to $0.4 \%$ ) and this is likely to attributable to the immunoregulatory role of vitamin $\mathrm{D}$ rather than a direct effect of vitamin D on thyroid function. Short duration of supplementation and low serum $25(\mathrm{OH}) \mathrm{D}$ levels (rather than the physiological levels) are likely reasons why the effects of vitamin $\mathrm{D}$ on thyroid function were not recovered in other studies [27]. Improved serum $25(\mathrm{OH}) \mathrm{D}$ status also significantly affected inflammation by decreasing hs-CRP which may provide a potential reason why improving 25 $(\mathrm{OH}) \mathrm{D}$ status promotes thyroid function. Given vitamin D's extensive roles in immune cell function and inflammation, these results are not surprising. Supplementation with vitamin $D$ has been found to induce tolerance $[50,51]$ and reduce auto reactivity in other autoimmune conditions such as multiple sclerosis [15, 52].
We utilized a nested case-control study design to further investigate the associations between thyroid function and vitamin D. Hypothyroid cases not taking thyroid medication had reduced TSH levels by $58 \%$ with a mean level that was within the reference range at follow-up. Large reductions in anti-thyroid antibody levels were found in cases with decreases in anti-TG by $66 \%$ and anti-TPO by $73 \%$. Changes in thyroid hormones and TSH were significantly correlated with improvement in hypothyroid symptoms assessed through thyroid assessment questionnaire and are clinically significant. Vitamin D deficient cases experienced greater reductions in biochemical signs of hypothyroidism and autoimmune thyroiditis. Vitamin D deficiency appeared to be a relevant risk factor for hypothyroidism and autoimmune thyroid disease, in addition to which supplementation with vitamin D provided measurable benefit.

The limitations of the study include the retrospective nature of the analyzes. Because the sample was drawn from a community-based program there is a selection bias to contend with, yet the extremely large sample size (over 11,000) must be considered a strength. Some risk factors associated with thyroid disease, such as cigarette smoking, were not available for all participants. The main strength of this study lies in the large number of thyroid function tests that were analyzed longitudinally to investigate the relationship between serum 25(OH)D status and these parameters.

\section{Conclusion}

Overall, the results of the current study suggest that for normal thyroid function an optimal $25(\mathrm{OH}) \mathrm{D}$ concentration above 100-125 nmol/L may be required. Although improving other nutrient status, like vitamin B12, should also be taken into consideration. Of concern, recommended daily intakes for vitamin $\mathrm{D}$ are aimed at achieving serum 25 $(\mathrm{OH}) \mathrm{D}$ concentrations of $50 \mathrm{nmol} / \mathrm{L}$ and targeted at bone health alone. Vitamin D offers a safe and economical approach to improve thyroid function and may provide protection from developing thyroid disease.

Acknowledgements We wish to thank Mr. Ken Fyie for his expertize preparing the dataset for this study and Dr. Brian Rankin for reviewing this manuscript.

Author contributions The authors' responsibilities were as follows: N.M., L.B., G.M. and S.K. designed the study; N.M. organized the data and performed for the statistical analysis; S.K., N.M., G.M and L. B. wrote the manuscript. All authors read and approved the final manuscript. 


\section{Compliance with ethical standards}

Conflict of interest S.K. and N.M. are employed by the Pure North S'Energy Foundation. The remaining authors declare that they have no competing interests.

Informed consent Informed consent was obtained from all individual participants included in the study.

Open Access This article is distributed under the terms of the Creative Commons Attribution 4.0 International License (http://crea tivecommons.org/licenses/by/4.0/), which permits unrestricted use, distribution, and reproduction in any medium, provided you give appropriate credit to the original author(s) and the source, provide a link to the Creative Commons license, and indicate if changes were made.

\section{References}

1. C.H. Blomquist, J.P. Holt, Chronobiology of the HypothalamicPituitary-Gonadal Axis in Men and Women. Biological Rhythms in Clinical and Laboratory Medicine. (Springer, Berlin), 1992)

2. M. Maes, K. Mommen, D. Hendrickx, D. Peeters, P. D'Hondt, R. Ranjan, F. De Meyer, S. Scharpe, Components of biological variation, including seasonality, in blood concentrations of TSH, TT3, FT4, PRL, cortisol and testestrone in healthy volunteers. Clin. Endocrinol. 46, 587-598 (1997)

3. M. Simoni, A. Velardo, V. Montanini, M. Faustini, S. Seghedoni, P. Marrama, Circannual rhythm of plasma thyrotropin in middleaged and old euthyroid subjects. Horm. Res. 33, 184-189 (1999)

4. I. Barchetta, M.G. Baroni, F. Leonetti, M. De Bernardinis, L. Bertoccini, M. Fontana, E. Mazzei, A. Fraioli, M.G. Cavallo, TSH levels are associated with vitamin D status and seasonality in an adult population of euthyroid adults. Clin. Exp. Med. 15, 389-396 (2015). https://doi.org/10.1007/s10238-014-0290-9

5. Y. Wang, E.J. Jacobs, M.L. McCullough, C. Rodriguez, M.J. Thun, E.E. Calle et al. Comparing methods for accounting for seasonal variability in a biomarker when only a single sample is available: insights from simulations based on serum 25hydroxyvitamin D. Am. J. Epidemiol. 170, 88-94 (2009)

6. A. Nanri, L.H. Foo, K. Nakamura, A. Hori, K. Poudel-Tandukar, Y. Matsushita, T. Mizoue, Serum 25-hydroxyvitamin D concentrations and season-specific correlates in Japanese adults. J. Epidemiol. 21, 346-353 (2011)

7. F. Baeke, T. Takiishi, H. Korf, C. Gysemans, C. Mathieu, Vitamin D: modulator of the immune system. Curr. Opin. Pharmacol. 10, 482-496 (2010)

8. C.D. Marques, A.T. Dantas, T.S. Fragoso, A.L. Duarte, The importance of vitamin D levels in autoimmune diseases. Rev. Bras. Reumatol. 50, 67-80 (2010)

9. K.L. Munger, L.I. Levin, J. Massa, R. Horst, T. Orban, A. Ascherio, Preclinical serum 25-hydroxyvitamin D levels and risk of type 1 diabetes in a cohort of US military personnel. Am. J. Epidemiol. 177, 411-419 (2013)

10. J. Mitri, M.D. Muraru., A.G. Pittas, Vitamin D and type 2 diabetes: a systematic review. Eur. J. Clin. Nutr. 65, 1005-1015 (2011)

11. M.F. Holick, Vitamin D: extraskeletal health. Endocrinol. Metab. Clin. N. Am. 39, 381-400 (2010)

12. J.P. Berg, G. Sornes, P.A. Torjesen, E. Haug, Cholecalciferol metabolites attenuate cAMP production in rat thyroid cells (FRTL-5). Mol. Cell. Endocrinol. 76, 201-206 (1991)
13. E. Vanoirbeek, A. Krishnan, G. Eelen, L. Verlinden, R. Bouillon, D. Feldman, A. Verstuyf, The anti-cancer and anti-inflammatory actions of 1,25(OH)2D3. Best Pract. Res. Clin. Endocrinol. Metab. 25, 593-604 (2011)

14. M.F. Holick, Vitamin D deficiency. N. Engl. J. Med. 357, 266-281 (2007)

15. S. Kimball, R. Vieth, H.M. Dosch, A. Bar-Or, R. Cheung, D. Gagne, P. O'Connor, C. D'Souza, M. Ursell, J.M. Burton, Cholecalciferol plus calcium suppresses abnormal PBMC reactivity in patients with multiple sclerosis. J. Clin. Endocrinol. Metab. 96, 2826-2834 (2011). https://doi.org/10.1210/jc.2011-0325

16. R.P. Heaney, Toward a physiological referent for the vitamin D requirement. J. Endocrinol. Invest. 37, 1127-1130 (2014)

17. G.A. Brent, Environmental exposure and autoimmune thyroid disease. Thyroid J. 20, 755-761 (2010)

18. J. Wang, S. Lv, G. Chen, Gao Ch, J. He, H. Zhong, Y. Xu, Metaanalysis of the association between Vitamin D and autoimmune thyroid disease. Nutrients 7, 2485-2498 (2015)

19. S. Kivity, N. Agmon-Levin, M. Zisappl, Y. Shapira, E.V. Nagy, K. Dankó, Z. Szekanecz, P. Langevitz, Y. Shoenfeld, Vitamin D and autoimmune thyroid diseases. Cell. Mol. Immunol. 8, 243-247 (2011)

20. G. Tamer, S. Arik, I. Tamer, D. Coksert, Relative vitamin D insufficiency in Hashimoto's thyroiditis. Thyroid J. 21, 891-896 (2011)

21. T. Yasuda, Y. Okamoto, N. Hamada, K. Miyashita, M. Takahara, F. Sakamoto, Serum vitamin D levels are decreased and associated with thyroid volume in female patients with newly onset Graves' disease. Endocrine 42, 739-741 (2012)

22. I. Clinckspoor, L. Verlinden, C. Mathieu, R. Bouillon, A Verstuyf, B. Decallonne, Vitamin D in thyroid tumorigenesis and development. Prog. Histochem. Cytochem. 48, 65-98 (2013)

23. A.M.H. Mackawy, B. Al-Ayed, B.M. Al-rashidi, Vitamin D deficiency and its association with thyroid disease. Int. J. Health Sci. 7, 267-275 (2013)

24. L. Chailurkit, W. Aekplakom, B. Ongphiphadhanakul, High vitamin D status in younger individuals is associatedwith low circulating thyrotropin. Thyroid J. 23, 25-30 (2013)

25. Q.Q. Zhang, M. Sun, Z.X. Wang, Q. Fu, Y. Shi, F. Yang, S. Zheng, J.J. Xu, X.P. Huang, X.Y. Liu, D. Cui, T. Yang, Relationship between serum 25-hydroxy vitamin $\mathrm{D}$ and thyroid autoimmunity among middle-aged and elderly individuals. Acta Universitatis Medicinalis Nanjung 34, 486-489 (2014)

26. D.Y. Shin, K.J. Kim, D. Kim, S. Hwang, E.J. Lee, Low serum vitamin $\mathrm{D}$ is associated with anti-thyroid peroxidase antibody in autoimmune thyroiditis. Yonesi Med. J. 55, 476-481 (2014)

27. S. Chaudhary, D. Dutta, M. Kumar, S. Saha, S.A. Mondal, A. Kumar, S. Mukhopadhyay, Vitamin D supplementation reduces thyroid peroxidase antibody levels in patients with autoimmune thyroid disease: an open-labeled randomized controlled trial. Indian J. Endocrinol. Metab. 20, 391-398 (2016)

28. E.E. Mazokopakis, M.G.. Papadomanolaki, K.C. Tsekouras, A.D. Evangelopoulos, D.A. Kotsiris, A.A. Tzortzinis, Is vitamin D related to pathogenesis and treatment of Hashimoto's thyroiditis? Hell J. Nucl. Med. 18, 222-227 (2015)

29. Y. Simsek, I. Cakir, M. Yetmis, O.S. Dizdar, O. Baspinar, F. Gokay, Effects of vitamin D treatment on thyroid autoimmunity. J. Res. Med. Sci. 21, 92 (2016)

30. P. De Remigis, L. Vianale, A. De Remingis, G. Napolitano, Vitamin D and autoimmune thyroid disease (at): preliminary results. Thyroid J. 23, A81-A82 (2013)

31. I.V. Pankiv, Impact of vitamin D supplementation on the level of thyroid peroxidase antibodies in patients with autoimmune hypothyroidism. Int. J. Endocrinol. (2016) 
32. J.R. Garber, R.H. Cobin, H. Gharib, J.V. Hennessey, I. Klein, J.I. Mechanick, R. Pessah-Pollack, P.A. Singer, K.A. Woeber, Clinical practice guidelines for hypothyroidism in adults. Endocr. Pract. 18, 988-1028 (2012)

33. T. Janz, C. Pearson, Vitamin D blood levels of Canadians. Stat. Can. 82-624-X (2011)

34. G. Muscogiuri, G. Tirabassi, G. Bizzaro, F. Orio, S.A. Paschou, A. Vryonidou, G. Balercia, Y. Shoenfeld, A. Colao, Vitamin D and thyroid disease: to D or not to D? Eur. J. Clin. Nutr. 69, 291-296 (2015)

35. Institute of Medicine, Food and Nutrition Board. Dietary Reference Intakes for Calcium and Vitamin D. National Academy Press, Washington, DC (2010)

36. L. Wartofsky, R.A. Dickey, The evidence for a narrower thyrotropin reference range is compelling. J. Clin. Endocrinol. Metab. 90, 5483-5488 (2005)

37. M.I. Surks, G. Goswami, G.H. Daniels, The thyrotopin reference range should remain unchanged. J. Clin. Endocrinol. Metab. 90, 5489-5496 (2005)

38. B. Biondi, The normal TSH reference range: what has changed in the last decade? J. Clin. Endocrinol. Metab. 98, 3584-3587 (2013)

39. L.M. Demers, C.A. Spencer, Laboratory Medicine Practice Guidelines: Laboratory Support for the Diagnosis and Monitoring of Thyroid Disease. Clin. Endocrinol. 58, 138-140 (2003)

40. V. Fatourechi, G.G. Klee., S.K. Grebe et al. Effects of reducing the upper limit of normal TSH values. JAMA 290, 3195-3196 (2003)

41. T. Navaneelan T, T. Janz, Adjusting the scales: Obesity in the Canadian population after correcting for respondent bias. Stat. Can. 82-624-X (2012)

42. N.C. Bozkurt, B. Karbek, B. Ucan, M. Sahin, E. Cakal, M. Ozbek, T. Delibasi, The association between severity of vitamin D deficiency and Hashimoto's thyroiditis. Endocr. Pract. 19, 479-484 (2013). https://doi.org/10.4158/EP12376

43. O.M. Camurdan, E. Doger, A. Bideci, N. Celik, P. Cinaz, Vitamin D status in children with Hashimoto thyroiditis. J. Pediatr. Endocrinol. Metab. 25, 467-470 (2012)

44. D.S. Cooper, B. Biondi, Subclinical thyroid disease. Lancet 379, 1142-1154 (2012)

45. A. Jabbar, A. Yawar, S. Waseem, N. Islam, N. Ul Haque, L. Zuberi, A. Khan, J. Akhter, Vitamin B12 deficiency common in primary hypothyroidism. J. Pak. Med. Assoc. 58, 258-261 (2008)

46. F.A. Al-Khamis, Serum Vitamin B12 and thyroid hormone levels in Saudi patients with multiple sclerosis. J. Fam. Community Med. 23, 151-154 (2016)

47. A. Antonelli, S. Ferrari, A. Corrado, A. Di Domenicantonio, P. Fallahi, Autoimmune thyroid disorders. Autoimmun. Rev. 14, 174-180 (2015). https://doi.org/10.1016/j.autrev.2014.10.016

48. Y. Zheng, J. Zhu, M. Zhou, L. Cui, W. Yao, Y. Liu, Meta-analysis of long-term vitamin D supplementation on overall mortality. PLoS One 8, e82109 (2013)

49. L.M. Demers, Thyroid disease: pathophysiology and diagnosis. Clin. Lab. Med. 24, 19-28 (2004)

50. R.F. Chun, P.T. Liu, R.L. Modlin, J.S. Adams, M. Hewison, Impact of vitamin D on immune function: lessons learned from genome-wide analysis. Front. Physiol. 5, 151 (2014). https://doi. org/10.3389/fphys.2014.00151

51. M. Hewison, Vitamin D and innate and adaptive immunity. Vitam. Horm. 86, 23-62 (2011). https://doi.org/10.1016/B978-012-386960-9.00002-2

52. J. Smolders, E. Peelen, M. Thewissen, J.W. Cohen Tervaert, P. Menheere, R. Hupperts, J. Damoiseaux, Safety and T cell modulating effects of high dose vitamin D3 supplementation in multiple sclerosis. PLoS One 5, e15235 (2010). https://doi.org/10. 1371/journal.pone.0015235 